\title{
High Power Factor Modular Polyphase AC/DC Converters with Galvanic Isolation Based on Resistor Emulators
}

\author{
Javier Sebastián, Ignacio Castro, Diego G. Lamar, Aitor Vázquez and Kevin Martín \\ Departamento de Ingeniería Eléctrica, Electrónica, de Computadores y Sistemas \\ University of Oviedo. \\ Gijón 33204, Spain \\ e-mail: sebas@uniovi.es
}

\begin{abstract}
This paper deals with a modular, isolated-output, polyphase, AC/DC converter based on the use of Resistor Emulators (REs). A RE is a DC/DC converter that behaves as a resistor at its input port. The value of this resistor (input impedance) is controlled by the converter duty cycle. In the proposed topology, all the REs are controlled to have the same input impedance, whose value is determined by the outputvoltage feedback loop. Also the power processed by each $R E$ is the same. As a consequence, the total power is distributed (and also the power losses), thus allowing us to build a modular system. Moreover, the behavior of these DC/DC converters as REs also allows their connection in series and/or in parallel with perfect sharing of voltage (when connected in series) and current (when connected in parallel). This fact makes possible to extend the proposed solution to high power applications.
\end{abstract}

Keywords-Polyphase AC/DC converters, Power Factor Correction, Modular Converters.

\section{INTRODUCTION}

Resistor Emulators (REs) [1-7] are DC/DC converters that behave like a resistor at their input port. This behavior is represented schematically by the dependent power source symbol shown in Fig. 1a. This behavior is obtained by choosing the proper converter control. Thus, the control based on an analog-multiplier and an input current feedback loop (see Fig. 2a) is the most popular one when the converter is operating in the Continuous Conduction Mode (CCM) [4, 5]. This type of control is called Multiplier-Based Control (MBC). However, some converters behave as "natural" REs when they have been designed to always operate in the Discontinuous Conduction Mode (DCM). In this case, they are controlled by the so called Voltage-Follower Control (VFC) (Fig. 2b). Moreover, behavior as "almost perfect" RE can also be

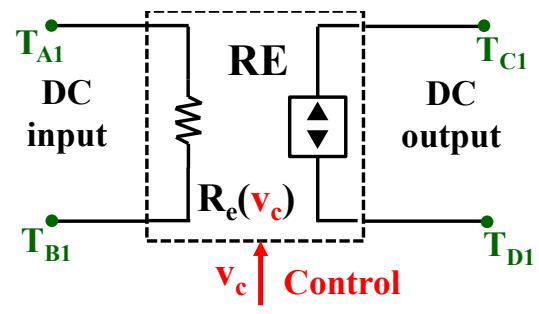

Fig. 1. Resistor Emulator concept.

This work has been supported by the Spanish Government under Project MINECO-13-DPI2013-47176-C2-2-R and the Principality of Asturias under the grants "Severo Ochoa" BP14-140 and BP14-85 and by the Project FC-15GRUPIN14-143 and by European Regional Development Fund (ERDF) grants. achieved using One-Cycle Control (OCC) [8-12] or VoltageControlled Compensation Ramp Control (VCCRC) [9, 13-14]

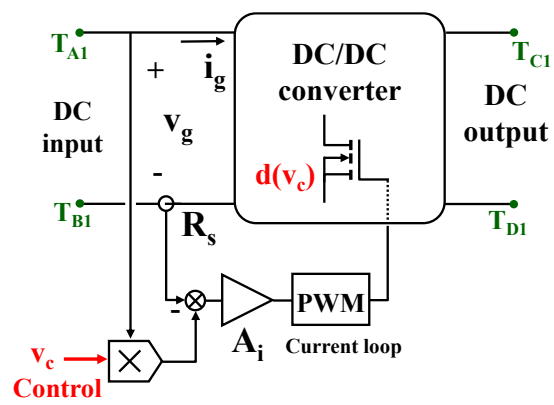

a)

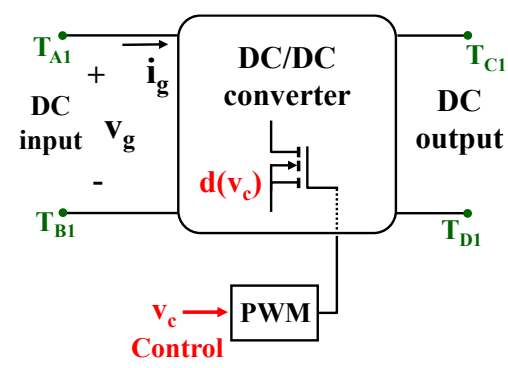

b)

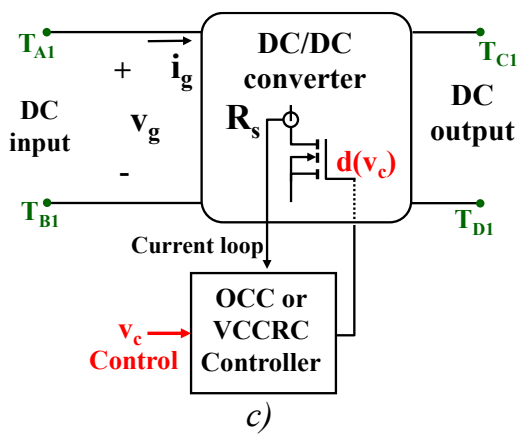

Fig. 2. Resistor Emulator implementations: a) MultiplierBased Control. b) Voltage-Follower Control. c) One-Cycle Control or Voltage-Controlled Compensation Ramp Control. 


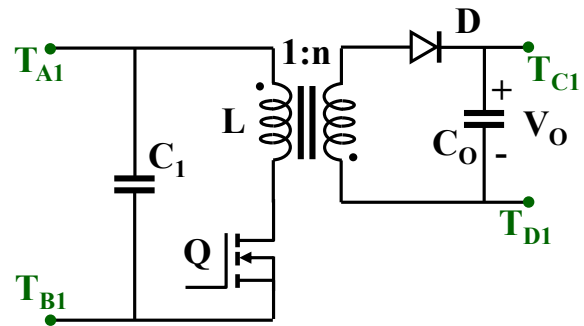

a)

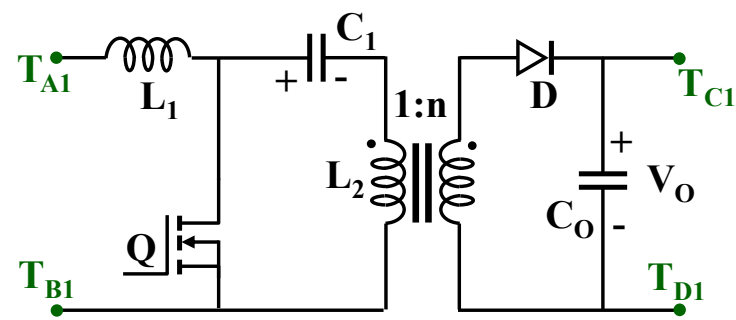

b)

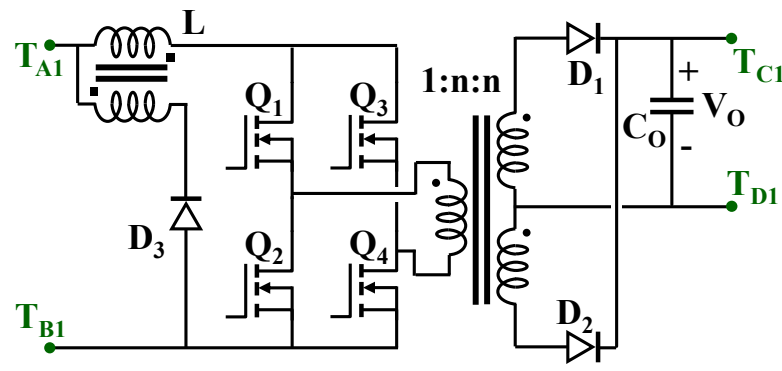

c)

Fig. 3. Examples of DC/DC converters suitable to be used as REs in the case of wide range of input voltage values: a) Flyback. b) SEPIC. c) Current-Fed Full Bridge.

(see Fig. 2c).

If a RE has to operate from very low values of input voltage, then a step-up converter must be selected as practical implementation of the RE power topology. Some examples of step-up converters suitable to be used as RE are the Boost [4], Flyback [5, 6] (see Fig. 3a), SEPIC [15, 16] (see Fig. 3b), Ćuk [16-17] and Zeta converters.

In the case of the Boost converter, ideal operation as RE is achieved by controlling the converter according to different strategies. Thus, if the converter is working in the CCM, ideal behavior as RE is obtained by using MBC. Operation as ideal $\mathrm{RE}$ is also achieved if the converter is operating just in the Boundary Conduction Mode (BCM), which means that the converter is always in the limit between CCM and DCM. On the other hand, operation near to ideal RE is obtained by controlling the converter according to the VFC, when the converter is working in the DCM [18-19]. The use of OCC allows operation as "almost perfect" RE, especially if the ripple of the current passing through the input inductor is negligible.
In the case of the Flyback, SEPIC, Cuk and Zeta converters, ideal RE behavior is obtained when these converters are working in the DCM [6, 15-17] and they are controlled with VFC. As in the case of any DC/DC converter, the use of MBC also allows perfect $\mathrm{RE}$ behavior (in the case of these converters even for very low input voltages). The modification of the OCC presented in $[13,14]$ also allows "almost perfect" RE without using a multiplier when these converters are operating in the CCM.

Flyback, SEPIC, Ćuk and Zeta converters present the important advantage of having galvanic isolation and overcurrent control possibility (when an overload takes place), which is not possible in the case of the Boost converter. However, these converters are used in relatively low power applications. More complex step-up converters, such as the Current-Fed Push-Pull [20] and the Current-Fed Full Bridge (Fig. 3c) combine relatively high power capability and galvanic isolation.

The main application of the RE is to perform Power factor Correction (PFC) in single-phase, front-end, AC/DC converters (Fig. 4) [4-6, 9, 11-19]. In this case, the cascade connection of a full-wave rectifier $\left(D_{1 \mathrm{p}}-\mathrm{D}_{2 \mathrm{~N}}\right)$, a $R E$ and a bulk capacitor $\mathrm{C}_{\mathrm{B}}$ (typically an electrolytic one) allows us to obtain an almost perfect sinusoidal line current and a DC output voltage. It should be noted that the size of the bulk capacitor $C_{B}$ is relatively large due to the instantaneous power handled by the $\mathrm{RE}$, which is pulsating at twice the line frequency.

The high-quality line current obtained using this very wellknown arrangement is due to the fact that diodes $D_{1 P}$ and $D_{2 N}$ remain conducting during the entire positive line half-cycle, whereas $\mathrm{D}_{2 \mathrm{P}}$ and $\mathrm{D}_{1 \mathrm{~N}}$ conduct the negative one. Unfortunately, the situation is very different when a full-wave rectifier is connected to a three-phase (or higher order) grid. In this case, the diodes cannot conduct $180^{\circ}$, but a lower angle. For example, in the case of the cascade connection of a threephase, full-wave rectifier $\left(\mathrm{D}_{1 \mathrm{P}}-\mathrm{D}_{3 \mathrm{~N}}\right)$, a $\mathrm{RE}$ and an output capacitor (see Fig. 5a), the line current angle is $120^{\circ}$, as shown in this figure. The situation is even worse with a higher order rectifier (the line waveform with a six-phase, full-wave rectifier

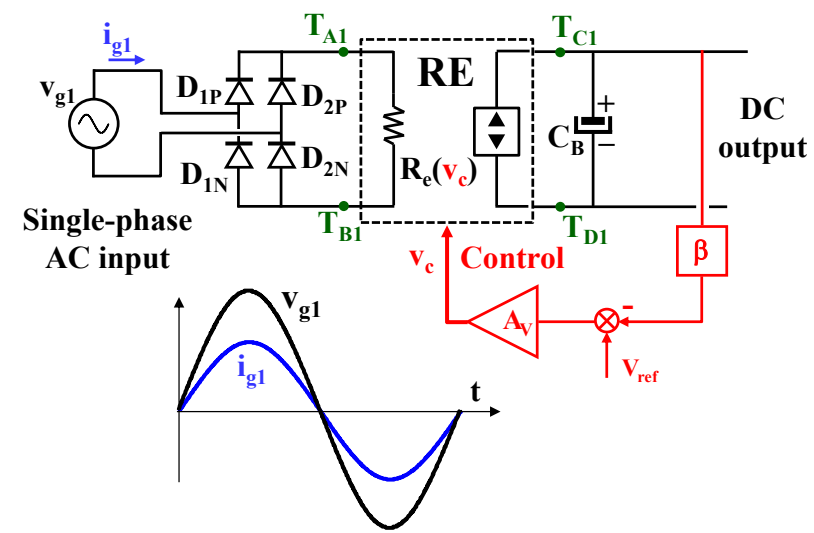

Fig. 4. Use of a RE for single-phase Power Factor Correction. 


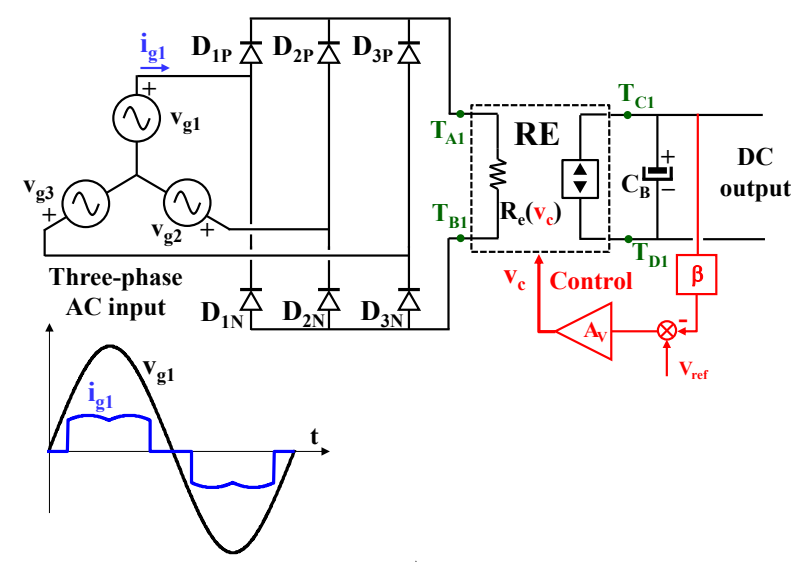

a)

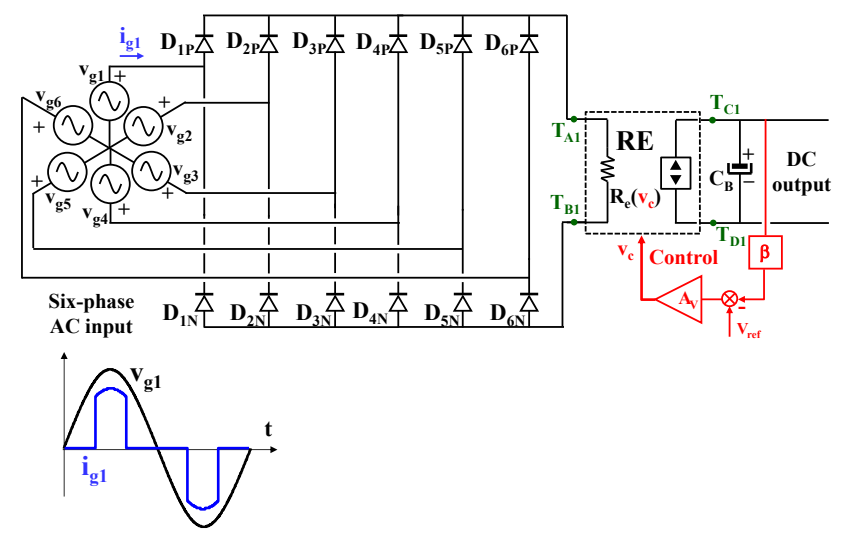

b)

Fig. 5. Use of a RE at the output of a full-wave, polyphase, rectifier. a) Three-phase case. b) Six-phase case.

is given in Fig. 5b). Due to this, the cascade connection of a full-wave rectifier and a RE is not the right solution to obtain perfect line current in the case of polyphase grids.

Many different power topologies have been proposed in the last years to overcome this problem [21], many of them without galvanic isolation. Among them, the one proposed in [22] achieves perfect sinusoidal line currents and galvanic isolation by using several REs instead of only one (see Fig. 6). In this case, three full-wave, single-phase rectifiers are connected in such a way that one of the input terminals of each single-phase rectifier is connected to each grid phase, whereas the other input terminals are connected together. For each fullwave, single-phase rectifier $x$, the pair of diodes $\mathrm{D}_{1 \mathrm{P} x}-\mathrm{D}_{2 \mathrm{~N} x}$ conducts for the positive half cycle of $v_{g x}$, whereas the pair of diodes $\mathrm{D}_{2 \mathrm{P} x}-\mathrm{D}_{1 \mathrm{~N} x}$ conducts for the negative one. Thus, a pair of diodes of each single-phase rectifier is always conducting and, therefore, a balanced load made up of three resistors (the three REs) is seen by the three-phase grid. As a consequence, the three grid currents are proportional to the corresponding grid voltages and unity power factor is achieved.

A different solution, also based on the use of REs, is proposed in this paper. Each RE is considered as a component of the overall converter, which allows the power conversion

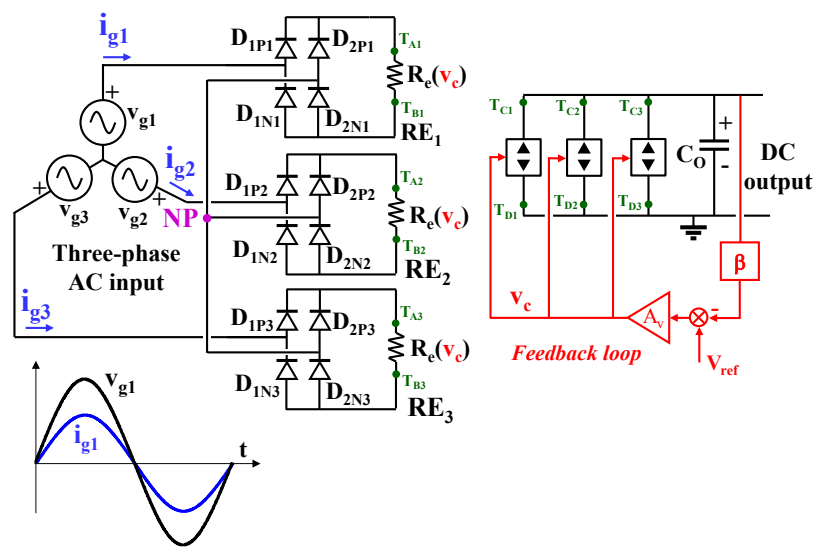

Fig. 6. The three-phase, RE based, AC/DC converter with galvanic isolation proposed in [22].

process to be spread among them, thus also spreading their power losses. As in $[22,23]$, each RE is controlled to exhibit the same equivalent input resistance $R_{e}\left(v_{c}\right)$, whose value is determined by the control voltage $v_{c}$, which is the output voltage of an output-voltage feedback loop. Furthermore, all the REs must have galvanic isolation between their input and output ports because the output ports must be connected each other. This connection can be in parallel (see Fig. 7a) or in series (see Fig. 7b). Also as in [22, 23], the power processed by all the REs is delivered to the same point. Therefore, the total power delivered is not pulsating in the case of polyphase grids. This fact allows the use of low-value capacitors (instead of large and bulky electrolytic ones) at the output of the overall converter, thus allowing its faster response.

\section{THE PROPOSED MODULAR POLYPHASE AC/DC CONVERTER WITH HIGH POWER FACTOR AND GALVANIC ISOLATION}

The proposed converter is based on the connection of the input of a RE in series with each rectifier diode in a full-wave

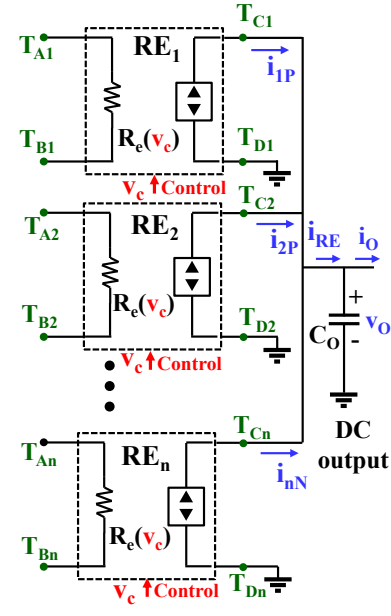

a)

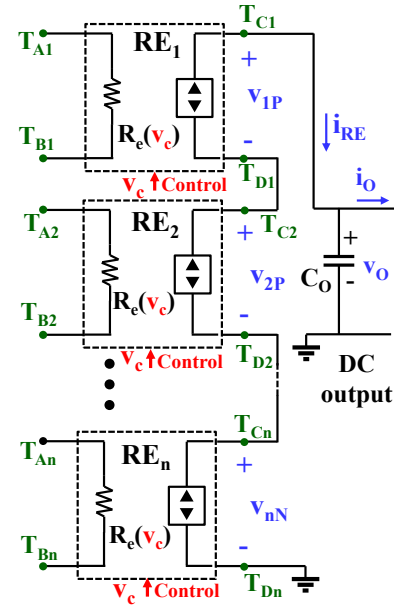

b)
Fig. 7. Connection of RE outputs: a) Parallel connection. b) Series connection. 


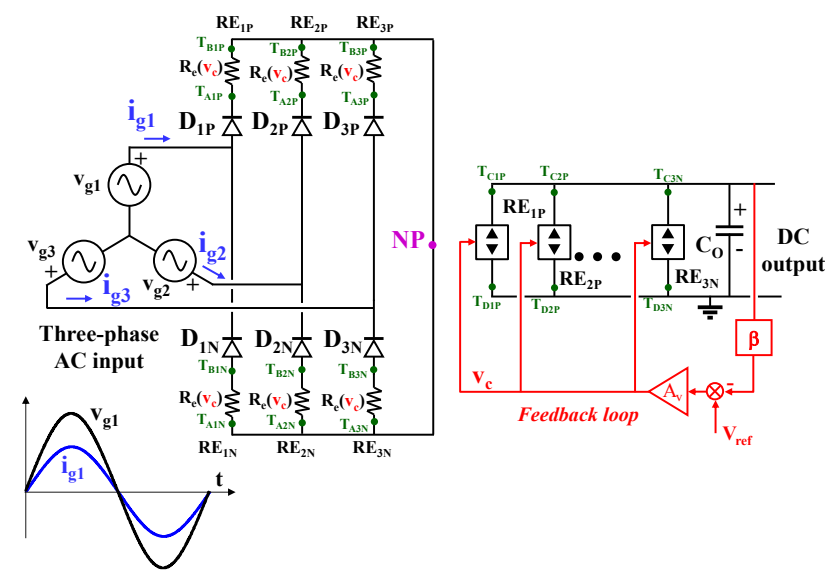

a)

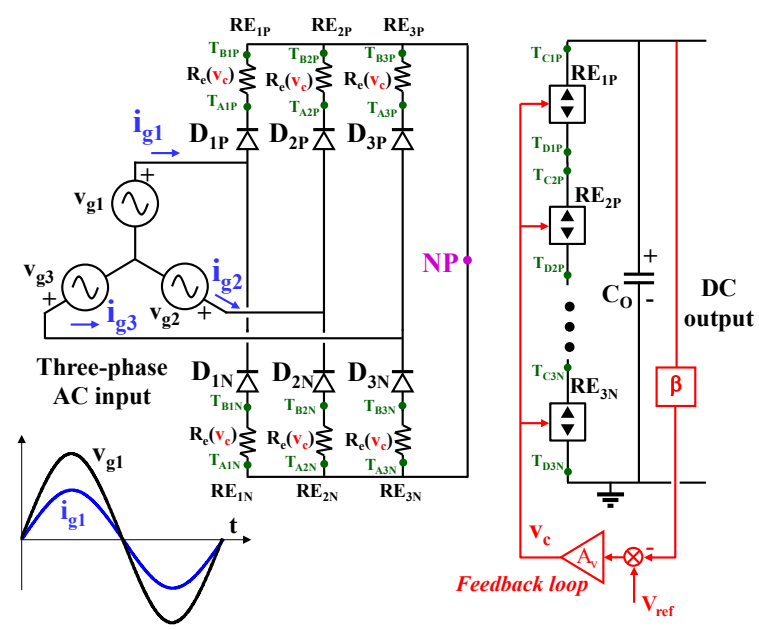

b)

Fig. 8. Proposed modular, isolated output, polyphase, AC/DC converter based on REs (three-phase implementation): a) Case of outputs in parallel connection. b) Case of outputs in series connection.

rectifier (see Fig. 8). All the RE outputs are connected in parallel (see Fig. 8a) or in series (see Fig. 8b) with each other, this connection being the converter output. The full-wave rectifier output is short-circuited in the neutral point NP. The power transfer is achieved from the RE inputs to their outputs, (which is the overall converter output) and it takes place every line half cycle. Thus, the total number of REs needed is $n=2 \cdot p$, where $p$ is the number of phases. It should be noted that each line current has to pass through $1 \mathrm{RE}$ and 1 rectifier diode when circulating from each input voltage source (phase voltage) $v_{g x}$ to the neutral point NP. In the case of the converters presented in [22-23], the total number of RE needed was $n=p$, which is a number of converters twice lower. However, each line current has to pass through $1 \mathrm{RE}$ and 2 rectifier diodes when circulating from each input voltage source to the neutral point NP. Therefore, for a given efficiency in the REs and for a given power processing capability, the proposed converter will exhibit better overall efficiency and will be capable of handling higher power levels than the ones proposed in [22-23].

The proposed solution can be used in any polyphase grid. However, for the sake of simplicity, the analysis is presented for a three-phase grid. The phase voltages and currents will be defined as (see Fig. 8):

$$
\begin{aligned}
& v_{g x}=V_{g} \sin \left[\omega_{\mathrm{g}} \mathrm{t}-\frac{2 \pi}{3}(x-1)\right] \\
& i_{g x}=\frac{v_{g x}}{R_{e}\left(v_{C}\right)} \quad(x=0,1,2),
\end{aligned}
$$

where $V_{g}$ is the peak value of the phase voltage, $\omega_{g}$ is the grid frequency, $R_{e}\left(v_{c}\right)$ is the resistance emulated by the REs (i.e., the input impedance of all the REs at frequencies as low as the line frequency), $v_{c}$ is the control voltage that determines the value of resistance emulated by the REs and $i_{g x}$ is the current passing through the phase $x$. As a consequence, the power handled by each RE can be expressed as:

$$
\begin{aligned}
& \text { - if } v_{g x}>0 \text {, then: } \\
& p_{x P}=\frac{v_{g x}^{2}}{R_{e}\left(v_{C}\right)}= \\
& =\frac{V_{g}^{2}}{2 R_{e}\left(v_{C}\right)}\left\{1-\cos \left[2 \omega_{\mathrm{g}} \mathrm{t}-\frac{4 \pi}{3}(x-1)\right]\right\} \\
& p_{x N}=0, \\
& \text { - if } v_{g x}<0, \text { then: } \\
& p_{x N}=\frac{v_{g}^{2}}{2 R_{e}\left(v_{C}\right)}\left\{1-\cos \left[2 \omega_{\mathrm{g}} \mathrm{t}-\frac{4 \pi}{3}(x-1)\right]\right\} \\
& p_{x P}=0,
\end{aligned}
$$

where $p_{x P}$ and $p_{x N}$ are the values of the power handled by the resistor emulator $\mathrm{RE}_{x \mathrm{P}}$ (those connected to diodes $\mathrm{D}_{x \mathrm{P}}$ ) and $\mathrm{RE}_{x \mathrm{~N}}$ (those connected to diodes $\mathrm{D}_{x \mathrm{~N}}$ ), respectively. The waveforms corresponding to the instantaneous power handled by each RE is given in Fig. 9.

The outputs of the REs behave as power sources [1-3] and, therefore, the values of the output voltages and currents depend
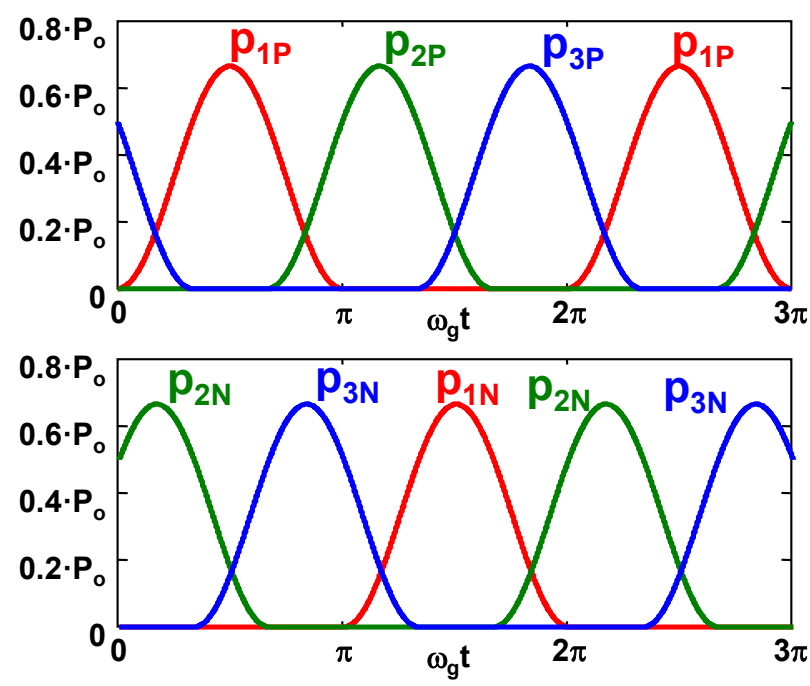

Fig. 9. Power handled for each RE. $P_{o}$ is the converter total power. 
on how these outputs have been connected. Thus, if the outputs are connected in parallel (see Fig. 7a), then all the REs have the same output voltage $v_{o}$. In this case, the current supplied by the REs is:

$$
\begin{aligned}
& \text { - if } v_{g x}>0, \text { then: } \\
& i_{x P}=\frac{v_{g}^{2}}{2 v_{o} R_{e}\left(v_{C}\right)}\left\{1-\cos \left[2 \omega_{\mathrm{g}} \mathrm{t}-\frac{4 \pi}{3}(x-1)\right]\right\} \\
& i_{x N}=0, \\
& \text { - if } v_{g x}<0, \text { then: } \\
& i_{x N}=\frac{V_{g}^{2}}{2 v_{o} R_{e}\left(v_{C}\right)}\left\{1-\cos \left[2 \omega_{\mathrm{g}} \mathrm{t}-\frac{4 \pi}{3}(x-1)\right]\right\} \\
& i_{x P}=0,
\end{aligned}
$$

where $i_{x P}$ and $i_{x N}$ are the values of the current supplied by the resistor emulators $\mathrm{RE}_{x \mathrm{P}}$ and $\mathrm{RE}_{x \mathrm{~N}}$, respectively. Fig. 10 shows the waveforms corresponding to these currents. The value of the total current injected into the parallel connection of the output capacitor $\mathrm{C}_{\mathrm{o}}$ and the load (not represented in Fig. 7a),

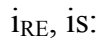

$$
i_{R E}=\sum_{x=1}^{3}\left(i_{x P}+i_{x N}\right)=\frac{3 V_{g}^{2}}{2 v_{o} R_{e}\left(v_{C}\right)} .
$$

This expression shows that AC components of twice the grid frequency are completely cancelled out and $i_{R E}$ is just a DC current. As a consequence, the output filter capacitor has to remove only the switching frequency components of the REs output current. As no power pulsating at the grid frequency has to be stored in the output capacitor (only power pulsating at the switching frequency), then the capacitor $\mathrm{C}_{\mathrm{o}}$ can be relatively small and it is free of voltage ripple of twice the grid frequency. Due to this, the compensator $A_{v}$ has not to remove any low frequency component and, therefore, the voltage loop can be relatively fast, clearly faster than in the case of a singlephase AC/DC converter [24-26].
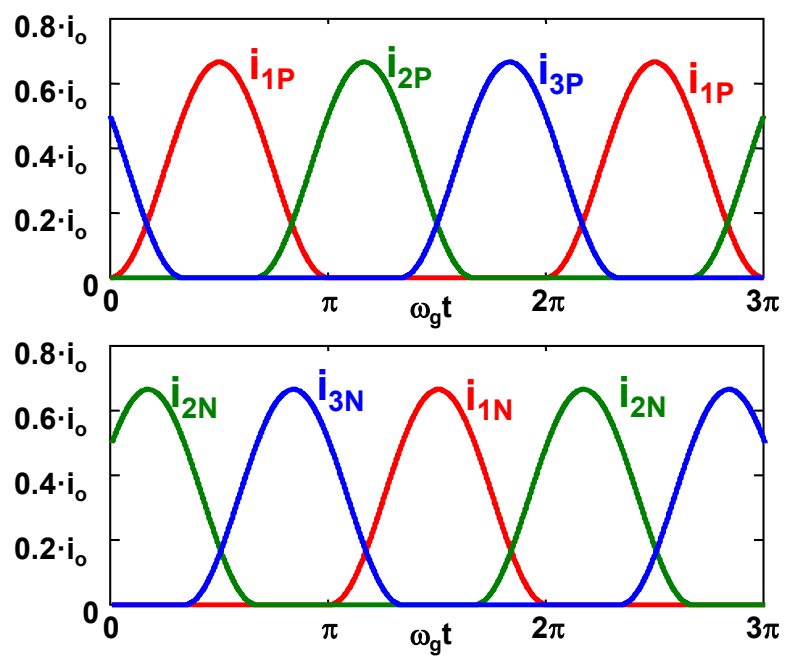

Fig. 10. Current passing through the output of each RE when the outputs have been connected in parallel (see Fig. $7 a$ and Fig. 8a).
If the outputs are connected in series (Fig. 7b), then all the REs have the same output current $i_{R E}$. In this case, the voltage at the output of each RE is:

$$
\begin{aligned}
& \text { - if } v_{g x}>0 \text {, then: } \\
& v_{x P}=\frac{V_{g}^{2}}{2 i_{R E} R_{e}\left(v_{C}\right)}\left\{1-\cos \left[2 \omega_{\mathrm{g}} \mathrm{t}-\frac{4 \pi}{3}(x-1)\right]\right\} \\
& v_{x N}=0 \text {, } \\
& \text { - if } v_{g x}<0 \text {, then: } \\
& v_{x N}=\frac{V_{g}^{2}}{2 i_{R E} R_{e}\left(v_{C}\right)}\left\{1-\cos \left[2 \omega_{\mathrm{g}} \mathrm{t}-\frac{4 \pi}{3}(x-1)\right]\right\} \\
& v_{x P}=0 \text {, }
\end{aligned}
$$

where $v_{x P}$ and $v_{x N}$ are the values of the voltage across the outputs of the resistor emulators $\mathrm{RE}_{x \mathrm{P}}$ and $\mathrm{RE}_{x \mathrm{~N}}$, respectively. The value of the voltage across the output capacitor $C_{o}$ and the load (not represented in Fig. 7b), $v_{o}$, is:

$v_{o}=\sum_{x=1}^{3}\left(v_{x P}+v_{x N}\right)=\frac{3 V_{g}^{2}}{2 i_{R E} R_{e}\left(v_{C}\right)}$.

As in the previous case, the AC components of twice the grid frequency are completely cancelled out and $v_{o}$ is just a DC voltage. The same considerations about the size of the output capacitor $\mathrm{C}_{\mathrm{o}}$ and the fast response of the converter output can be applied in this case. The waveforms in this case are as the ones shown in Fig. 10, but replacing $i_{o}, i_{x P}$ and $i_{x N}$ with $v_{o}, v_{x P}$ and $v_{x N}$, respectively.

\section{POWER TOPOLOGIES FOR THE RESISTOR EMULATORS}

The total power supplied by the overall AC/DC converter in the case of a three-phase grid is the addition of the power handled by the six REs:

$$
P_{o}=\sum_{x=1}^{3}\left(p_{x P}+p_{x N}\right)=\frac{3 V_{g}^{2}}{2 R_{e}\left(v_{C}\right)} .
$$

Therefore, the average power handled by each RE is:

$$
P_{1 R E}=\frac{P_{o}}{6}=\frac{V_{g}^{2}}{4 R_{e}\left(v_{C}\right)} \text {. }
$$

In the case of $p$-phase grid, (19) becomes:

$$
P_{1 R E}=\frac{P_{o}}{2 p} \text {. }
$$

$P_{\text {IRE }}$ determines the power to be handled by each RE and therefore, the type of power topology suitable for each specific case. Flyback's family of converters (SEPIC, Ćuk and Zeta) is adequate to implement REs up to $200 \mathrm{~W}$ (considering Si power semiconductor devices). Galvanic isolated versions of the Boost converter (e.g., the Current-Fed Full Bridge converter shown in Fig. 3c) are suitable for REs in the range of a few $\mathrm{kW}$. Also, the cascade connection of a Boost converter and a "DC transformer" (a DC/DC converter working at constant duty cycle to achieve soft-switching and, therefore, high efficiency) is an attractive alternative (see Fig. 11). 


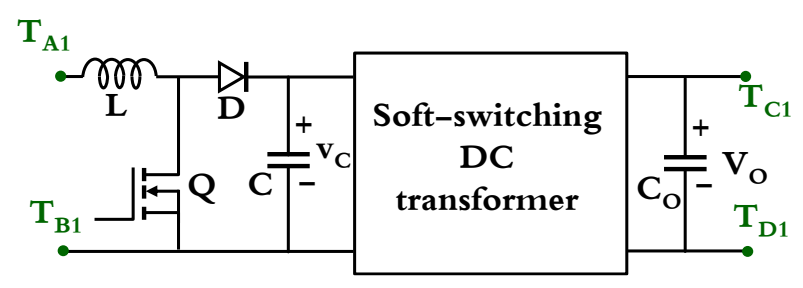

Fig. 11. Implementation of a RE with galvanic isolation to achieve a medium power, high efficiency, cell.

Moreover, the power processing capability can be increased by replacing each RE with the connection of several of them in series and/or parallel (see Fig. 12). It should be noted that ideal current and voltage sharing is achieved if the REs are properly controlled to have the same input impedance $R_{e}\left(v_{c}\right)$. Finally, the topology can be extended to be used not only in three-phase grids, but also in polyphase grids.

\section{CONTROL OF THE POWER TOPOLOGIES SUITABLE OF BEING USED AS RESISTOR EMULATORS}

Regarding the control of REs, several control strategies can be used to achieve RE behavior. The most useful are the following ones:

\section{Multiplier-Based Control, MBC (see Fig.2a).}

This control method is very well known because many single-phase, power factor correctors use controllers based on this method. Assuming that the gain of error amplifier of the current loop $A_{i}$ is high enough at grid frequencies, the average value (averaged in a switching period) of the input current $i_{g}$ is determined by the multiplier as follows:

$$
i_{g}=\frac{K_{M}}{R_{S}} v_{g} v_{c}
$$

where $K_{M}$ is a constant determined by the multiplier and $R_{S}$ is the gain of the current sensor. Therefore, the input impedance of the RE is:

$$
R_{e}\left(v_{c}\right)=\frac{v_{g}}{i g}=\frac{R_{S}}{K_{M}} \cdot \frac{1}{v_{c}} .
$$

This control method can be used when the converter is working in both CCM and DCM.

\section{Voltage-Follower Control, VFC (see Fig. 2b).}

This control method is only possible if the converter is

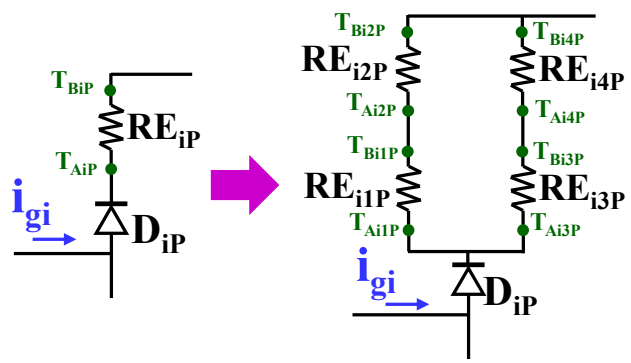

Fig. 12. Use of several REs (instead of just one) to increase the converter power capability. working in the DCM (for converters derived from the Flyback converter, such as the SEPIC, Ćuk and Zeta) or just in the $\mathrm{BCM}$ (for the Boost converter). In the case of converters belonging to the Flyback's family, the average value (averaged in a switching period) of the input current $i_{g}$ is determined by Faraday's law as follows:

$$
i_{g}=\frac{T_{s} d^{2}}{2 L} v_{g}
$$

where $T_{s}$ is the switching period, $d$ is the converter duty cycle and $L$ is the inductance of the primary side of the Flyback transformer. In the case of SEPIC, Ćuk and Zeta converters, $L$ is the equivalent inductance of the converter inductors in parallel and referring their values to the transformer primary side. From (22), the value of $R_{e}$ is:

$R_{e}(d)=\frac{v_{g}}{i g}=\frac{2 L}{T_{S}} \cdot \frac{1}{d^{2}}$.

If the duty cycle $d$ is obtained from a sawtooth waveform in a PWM controller, then its value is given by:

$$
d=\frac{v_{c}}{V_{P V}}
$$

where $V_{P V}$ amplitude of the sawtooth waveform. Therefore, (23) becomes:

$$
R_{e}\left(v_{c}\right)=\frac{2 L V_{P V}^{2}}{T_{s}} \cdot \frac{1}{v_{c}^{2}} .
$$

In the case of a Boost converter operating in the BCM, the average value (averaged in a switching period) of $i_{g}$ is: determined by Faraday's law as follows:

$$
i_{g}=\frac{T_{S} d}{2 L} v_{g}
$$

From (24) and (26), the value of $R_{e}\left(v_{c}\right)$ is easily obtained:

$$
R_{e}\left(v_{c}\right)=\frac{2 L V_{P V}}{T_{s}} \cdot \frac{1}{v_{c}} .
$$

\section{One-Cycle Control, OCC and Voltage-Controlled Compensation Ramp Control, VCCRC (see Fig. 2b).}

In the case of the Boost converter [9-13], the grid current is given by:

$$
i_{g}=\frac{v_{g}}{v_{o}}\left[\frac{v_{c}}{R_{S}}-\frac{\left(v_{o}-v_{g}\right) T_{S}}{2 L}\right] .
$$

This last equation shows that if the quotient $L / T_{s}$ satisfies the relationship:

$$
\frac{L}{T_{S}} \gg \frac{\left(v_{o}-v_{g}\right) R_{S}}{2 v_{c}},
$$

then $i_{g}$ and $v_{g}$ will be proportional, performing ideal RE behavior (this relationship means that the inductor current ripple is relatively small). In this case, the input impedance of $\mathrm{RE}$ is:

$$
R_{e}\left(v_{c}\right)=R_{s} v_{o} \cdot \frac{1}{v_{c}}
$$

In the case of the converter belonging to the Flyback family, the direct application of the OCC as given in [11] is quite complex and an alternative solution was proposed in [13, 14]. 
In this case, an exponential ramp is used instead of a linear one. This control is called VCCRC. The time constant of the exponential ramp $\tau$ defines the parameter $\mu$ as follows:

$$
\mu=\frac{T_{s}}{\tau} \text {. }
$$

The actual value of the input current is [13]:

$$
i_{g}=\frac{v_{o}}{v_{o}+n v_{g}}\left[\frac{v_{c}\left(e^{-\frac{v_{O}}{v_{O}+n v_{g}} \mu}-e^{-\mu}\right)}{R_{S}\left(1-e^{-\mu}\right)}-\frac{v_{o} v_{g} T_{S}}{2 L\left(v_{o}+n v_{g}\right)}\right] \text {. }
$$

The values of $\mu$ can be selected in such a way that the THD of this current when $v_{g}$ is changing sinusoidaly is minimized for each value of $M=v_{o} / n V_{g}$ ( $V_{g}$ being the peak value of $v_{g}$ ) and for each value of the parameter $\alpha$ defined as:

$$
\alpha=\frac{L}{L_{\text {crit_ } \_}},
$$

where $L_{\text {crit } \pi}$ is the value of $L$ that guarantees operation in the $\mathrm{CCM}$ during the entire line period for a given value of $v_{c}$. It should be noted that (32) is only valid if the converter is working in the CCM [13] during the line period, what implies a value of $L$ higher than $L_{c r i t} \pi$ (i.e., $\alpha>1$ ).

After minimizing the THD for each value of $M$ and $\alpha$, (32) becomes:

$$
i_{g}=\frac{\gamma(M, \alpha) v_{g} v_{c}}{R_{S} V_{g}}
$$

the values of $\gamma(M, \alpha)$ being represented in Fig. 13. From (34), it can be easily obtained:

$$
R_{e}\left(v_{c}\right)=\frac{R_{s} V_{g}}{\gamma(M, \alpha)} \cdot \frac{1}{v_{c}}
$$

\section{EXPERIMENTAL RESULTS}

The experimental validation has been carried out by using Flyback converters as REs. These Flybacks have been designed to work in the DCM in all the range of power. Due to this, VFC has been used to control each RE, which is a very simple control method. Based on the use of six of these Flyback converters, a three-phase prototype of AC/DC converter (see Fig. 8a) has been designed and built. In this converter, the RE outputs have been connected in parallel. The overall converter power is $250 \mathrm{~W}$ (Output: $48 \mathrm{~V} / 5.16 \mathrm{~A}$ ). The converter has been designed for the European voltage range (400 V line voltage),

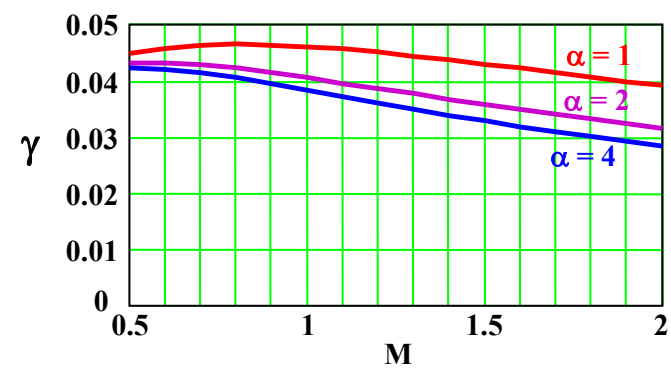

Fig. 13. Values of $\gamma$.

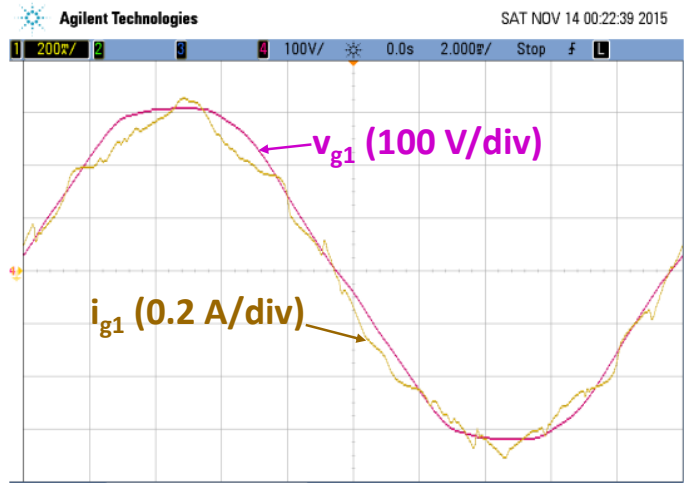

Fig. 14. Grid current and voltage in a phase.

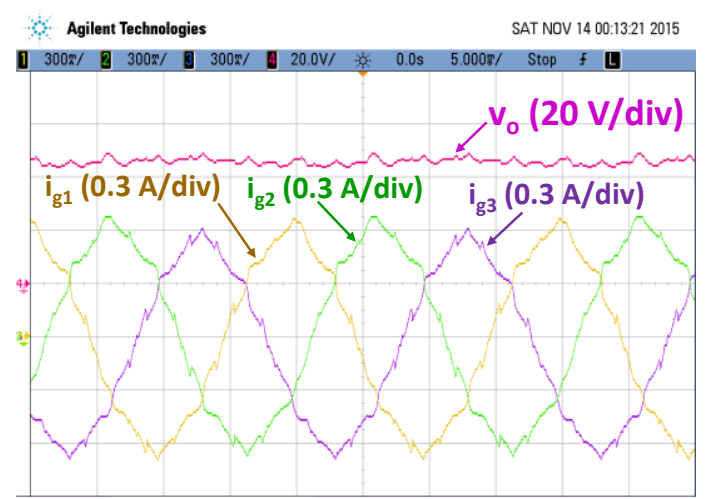

Fig. 15. Grid currents and output voltage.

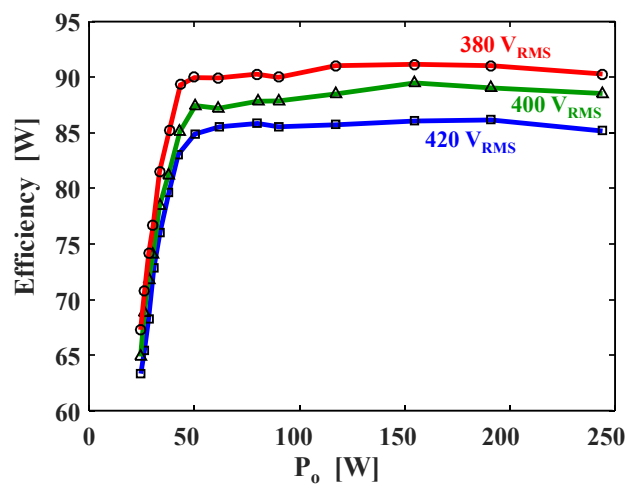

Fig. 16. Converter efficiency versus output power and grid voltage.

achieving 99.68\% power factor and 6.5\% THD. As Fig. 14 shows, grid current and voltage are in phase.

The measurements have been done with the converter connected to the real power grid, and using a resistive load at the overall converter output. The waveforms have been extracted as data from the oscilloscope and analyzed with the use of MATLAB ${ }^{\circledR}$. The grid currents $\left(i_{g 1}, i_{g 2}\right.$ and $\left.i_{g 3}\right)$ are shown in Fig. 15, as well as, the output voltage obtained with a $10 \mu \mathrm{F}$ film capacitor at the overall converter output.

It should be noted that, as a three-phase balanced system, it must comply with the IEC 1000-3-2 regulations in Class A [2729]. The measured grid currents have been analyzed and 
compared with the limits imposed by those regulations, the measured harmonics being well below these limits.

Finally, the efficiency of the converter is roughly $88 \%$ at maximum load (see Fig. 16)

\section{CONCLUSIONS}

A polyphase $\mathrm{AC} / \mathrm{DC}$ converter with galvanic isolation and very high power factor (ideally 1 ) is presented in this paper. The converter is made up of several (twice the number of phases) REs, which are DC/DC converters controlled to exhibit the same input impedance. The value of this input impedance is determined by an output-voltage feedback loop, which is the feedback loop of the overall AC/DC converter.

The use of REs as building blocks of the overall AC/DC converter allows us not only to achieve ideal power factor and THD, but also to distribute the total power among identical DC/DC converters, that can be considered as independent devices. Moreover, as the instantaneous input power is not time-depending, the instantaneous output power is not pulsating at twice the grid frequency and, therefore, the converter output capacitor is in charge of removing only the components of the switching frequency. As a consequence, this capacitor is relatively small and the output voltage feedback loop can be relatively fast.

Many different power topologies can be used to implement REs and they can be controlled according to several control strategies, which are briefly described in this paper. Moreover, the use of REs as building blocks of converters makes easy to scale up the power handled by the overall converter due to the ideal share of voltage and current obtained by connecting REs in series and in parallel.

Finally, a small prototype of the proposed converter has been built and tested. This prototype is based on six Flyback converters working in the DCM to achieve RE behavior using VFC.

\section{REFERENCES}

[1] S. Singer, "Realization of loss-free resistive elements", IEEE Trans. on Circuits and Systems, vol. 37, no. 1, pp. 54-60, Jan. 1990.

[2] S. Singer and R.W. Erickson, "Power-source element and its properties", IEE Proc.-Circuits Devices and Syst., vol. 141, no. 3, pp. 220-226, Jun. 1994.

[3] S. Singer and R.W. Erickson, "Canonical modeling of power processing circuits based on the POPI concept", IEEE Trans. on Power Electronics, vol. 7, no. 1, pp. 37-43, Jan. 1992.

[4] L. H. Dixon, "High power factor preregulators for off-line power supplies", Unitrode Power Supply Design Seminar, 1988, pp. 6.1-6.16.

[5] M. J. Kocher and R. L. Steigerwald, "An ac-to-dc converter with high quality input waveforms", IEEE Trans. on Industry Applications, vol. 19, no. 4, pp. 586-599, Jul/Aug. 1983.

[6] R. Erickson, M. Madigan and S. Singer, "Design of a simple high-power factor rectifier based on the flyback converter", Proc. IEEE APEC 1990, pp. 792-801.

[7] R. Erickson and D. Maksimovic, "Fundamentals of Power Electronics" (Second Edition). Kluwer Academic Publishers.

[8] K. M. Smedley and S. Cuk, "One-cycle control of switching converters", IEEE Trans. on Power Electronics, vol. 10, no. 6, pp. 625-633, Nov. 1995.
[9] J. P. Gegner and C. Q. Lee, "Linear peak current mode control: A simple active power factor correction control technique", Proc. IEEE PESC 1996, pp. 196-202.

[10] Z. Lai and K. M. Smedley, "A general constant-frequency pulsewidth modulator and its applications," IEEE Trans. on Circuits and Systems I, vol. 45, no. 4, pp. 386-396, Apr. 1998.

[11] Z. Lai and K. M. Smedley, "A family of continuous-conduction-mode power-factor-correction controllers based on the general pulse-width modulator". IEEE Trans. on Power Electronics, vol. 13, no. 3, pp. 501-510, May 1998.

[12] R. Brown and M. Soldano, "One cycle control IC simplifies PFC designs", Proc. IEEE APEC 2005, pp. 825-829.

[13] J. Sebastián, D. G. Lamar, M. Arias, M. Rodríguez and A. Fernández, "The Voltage-Controlled Compensation Ramp: A waveshaping technique for power factor correctors", IEEE Trans. on Industry Applications, vol. 45, $\mathrm{n}^{\circ} 3$, pp. 1016-1027, May/Jun. 2009.

[14] D. G. Lamar, M. Arias, A. Rodríguez, A. Fernández, M. M. Hernando and J. Sebastián. "Design-oriented analysis and performance evaluation of a low-cost high-brightness LED driver based on flyback power factor corrector", IEEE Transactions on Industrial Electronics, vol. 60, no. 7, pp. 2614-2626, Jul. 2013.

[15] J. Sebastián, J. Uceda, J. A. Cobos, J. Arau, and F. Aldana, "Improving power factor correction in distributed power supply systems using PWM and ZCS-QR SEPIC topologies". Proc. IEEE PESC 1991, pp. 780-791.

[16] D. S. L. Simonetti, J. Sebastián and J. Uceda, "The discontinuous conduction mode SEPIC and Cuk power factor preregulators: analysis and design", IEEE Trans. on Industrial Electronics, vol. 44, no. 5, pp. 630-637, Oct. 1997.

[17] M. Brkovic and S. Cuk, "Input current shaper using Cuk converter", Proc. INTELEC 1992, pp. 532-539.

[18] J. Lazar and S. Cuk, "Open loop control of a unity power factor, discontinuous conduction mode boost rectifier", Proc. INTELEC 1995, pp. 671-677.

[19] K. H. Liu and Y. L. Lin, "Current waveform distortion in power factor correction circuits employing discontinuous-mode boost converter", Proc. IEEE PESC 1989, pp. 825-829.

[20] V. J. Thottuvelil, T. G. Wilson and H. A. Owen, "Analysis and design of a Push-Pull current-fed converter”, Proc. IEEE PESC 1981, pp. 192-203.

[21] B. Singh, B. N. Singh, A. Chandra, K. Al-Haddad, A. Pandey and D. P. Kothari, "A review of three-phase improved power quality AC-DC converters", IEEE Trans. on Industrial Electronics, vol. 51, no. 3, pp. 641-660, Jun. 2004.

[22] S. Singer and A. Fuchs, "Multiphase AC-DC conversion by means of loss-free resistive networks", IEE Proc.-Circuits Devices and Syst., vol. 143, no. 4, pp. 233-240, Aug. 1996.

[23] U. Kamnarn and V. Chunkag, "Analysis and design of a modular threephase AC-to-DC converter using Cuk rectifier module with nearly unity power factor and fast dynamic response", IEEE Trans. on Power Electronics, vol. 24, no. 8, pp. 2000-2012, Aug. 2009.

[24] J. Sebastián, D. G. Lamar, M. M. Hernando, A. Rodríguez, and A. Fernández, "Steady-state analysis and modeling of power factor correctors with appreciable voltage ripple in the output-voltage feedback loop to achieve fast transient response" IEEE Trans. on Power Electronics, vol. 24, no. 11, pp. 25552566, Nov. 2009.

[25] J. Sebastián, D. G. Lamar, A. Rodríguez, M .Pérez, and A. Fernández, “On the maximum bandwidth attainable by power factor correctors with a standard compensator" IEEE Trans. on Industry Applications, vol. 46, no. 4, pp. 14851497, Jul/Aug. 2010.

[26] A. Fernández, J. Sebastián, P. Villegas, M. M. Hernando and D. G. Lamar, "Dynamic limits of a power-factor preregulator", IEEE Trans. on Industrial Electronics, vol. 52, no. 1, pp. 77-87, Feb. 2005.

[27] Electromagnetic Compatibility (EMC)-Part 3: Limits-Section 2: Limits for Harmonic Current Emissions (Equipment Input current $<16$ A per Phase), IEC1000-3-2, 1995

[28] Draft of the Proposed CLC Common Modification to IEC 61000-3-2 Document, 2006.

[29] Draft of the Proposed CLC Common Modification to IEC 61000-3-2/A2 Document, 2010. 